Research paper

\title{
Exploring the understanding and experience of working memory in teaching professionals: A large-sample questionnaire study
}

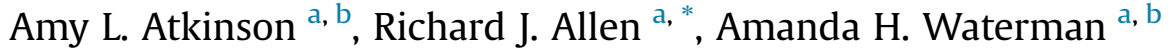 \\ a School of Psychology, University of Leeds, Leeds, West Yorkshire, LS2 9JT, UK \\ ${ }^{\mathrm{b}}$ Centre for Applied Education Research (CAER), Bradford Institute for Health Research, Bradford, West Yorkshire, BD9 6RJ, UK
}

\section{H I G H L I G H T S}

- First large-scale questionnaire on teachers' understanding of working memory.

- Most respondents demonstrated some, albeit incomplete, knowledge of working memory.

- Most respondents overestimated the duration limits of working memory.

- Large variation regarding possible support identified for children with poor working memory.

- Teacher training should include guidance on working memory in the classroom.

\section{A R T I C L E I N F O}

\section{Article history:}

Received 17 September 2020

Received in revised form

11 February 2021

Accepted 26 March 2021

Available online 12 April 2021

\section{Keywords:}

Working memory

Cognition

Teacher understanding

Cognitive load

\begin{abstract}
A B S T R A C T
Working memory (WM) underpins learning and is strongly associated with academic achievement. Children with poor WM need support in the classroom, but little is known about teachers' understanding of WM. An online questionnaire $(N=1425)$ assessed educational professionals' understanding of key concepts related to WM. Respondents generally showed some understanding, although most overestimated WM duration. There was also considerable variability in the signs identified as being associated with poor WM and possible strategies to assist such children. This demonstrates the need to provide teacher training about WM, and for collaboration between researchers and teachers in developing support materials.
\end{abstract}

๑ 2021 The Authors. Published by Elsevier Ltd. This is an open access article under the CC BY license (http://creativecommons.org/licenses/by/4.0/).

\section{Introduction}

Working memory refers to an individual's ability to simultaneously store and process a limited amount of information for a brief period of time (Baddeley, Hitch, \& Allen, 2021; Cowan, 2017). It increases linearly throughout childhood and adolescence until approximately $14-15$ years of age, when performance is considered to reach adult-like levels (Gathercole, Pickering, Ambridge, \& Wearing, 2004a). At every stage of development, there are large individual differences in working memory. For instance, Alloway (2006) reported that 6.5-year-old children on the 90th percentile exhibited performance similar to typical 9.5-year olds, whilst children on the 10th percentile achieved scores matching typical 4.5-year-olds. Thus, within a single classroom, performance on a

\footnotetext{
* Corresponding author.

E-mail address: r.allen@leeds.ac.uk (R.J. Allen).
}

working memory task might span five years of typical development, with at least some children exhibiting severe deficits. Working memory impairments are also a common feature of several developmental disorders and learning difficulties, including Attention Deficit Hyperactivity Disorder (ADHD; Martinussen, Hayden, Hogg-Johnson, \& Tannock, 2005), Developmental Coordination Disorder (DCD; Alloway, 2007; Alloway \& Archibald, 2008), Specific Language Impairment (SLI; Alloway \& Archibald, 2008; Archibald \& Gathercole, 2006), and dyslexia (Beneventi, Tønnessen, Ersland, \& Hugdahl, 2010; Smith-Spark \& Fisk, 2007).

Individual differences in working memory have important implications in educational settings, as working memory is considered to be essential for learning and a strong predictor of academic achievement (Alloway \& Alloway, 2010; Alloway, Alloway, \& Wootan, 2014; Gathercole, Pickering, Knight, \& Stegmann, 2004b; Holmes \& Adams, 2006). For instance, Alloway and Alloway (2010) found that working memory at five years of age predicted academic 
achievement at 11 years of age better than IQ. This relationship is unsurprising when one considers the vast number of classroom activities that rely on working memory. For example, within classroom settings, children are often required to follow lengthy series of instructions, such as "put your reading book away, get your maths worksheet, write your name at the top, and complete the first ten questions" (Gathercole, Lamont, \& Alloway, 2006). These instructional sequences place heavy demands on working memory, as children are required to store the sequence whilst they perform the series of actions (Waterman et al., 2017; Gathercole, Durling, Evans, Jeffcock, \& Stone, 2008; Jaroslawska, Gathercole, Logie, \& Holmes, 2016). Children with poor working memory also often have difficulties with other classroom-based activities, such as solving problems and monitoring the quality of their work (Alloway, Gathercole, Kirkwood, \& Elliott, 2009; Gathercole \& Alloway, 2008). They are also often described as forgetful, reserved in group settings, and reluctant to volunteer answers (Gathercole \& Alloway, 2008). Although most of these difficulties will occur as a direct result of their working memory impairments, some behaviors (such as being reserved or withdrawn) may reflect children disengaging as a result of interactions with teachers who do not fully understand the underlying reasons for their difficulties (Elliott, Gathercole, Alloway, Holmes, \& Kirkwood, 2010).

Children with poor working memory may also struggle with many subject-specific learning activities. For example, when conducting mental arithmetic, individuals must store the initial numbers and any interim results whilst performing the necessary operations needed to complete the task (Alloway, 2006; Fürst \& Hitch, 2000). Similarly, when reading, working memory is essential for the maintenance and linkage of separate phonological components in order to recognize a word, and to enable the ongoing integration of information in a text to produce meaning. For instance, one may need to encode several physical and personality descriptions and combine these into a coherent representation of a character (Cain, Oakhill, \& Bryant, 2004; Cowan, 2014; Preßler, Könen, Hasselhorn, \& Krajewski, 2014). If information is lost during these activities, individuals can either attempt to re-access the information, guess, or abandon the task completely (Gathercole, 2008). If the child is able to re-access the information, they may be able to complete the task successfully. However, when the information is no longer available, they must choose from the latter options. Both are likely to lead to missed learning opportunities, which when occurring frequently, can significantly restrict learning (Gathercole \& Alloway, 2008; Holmes, Gathercole, \& Dunning, 2010; Rowe, Titterington, Holmes, Henry, \& Taggart, 2019).

Given the pervasive difficulties that children with poor working memory face in the classroom, psychological research has attempted to identify ways to enhance working memory in children. An approach which has received considerable attention is working memory training (Dunning \& Holmes, 2014; Klingberg et al., 2005). This involves individuals repeatedly practicing working memory tasks or being trained to apply specific strategies that are thought to enhance working memory (e.g. rehearsal, chunking; Morrison \& Chein, 2011). There is, however, currently insufficient evidence to suggest that working memory training results in fartransfer effects to key secondary outcomes such as academic achievement (Melby-Lervåg \& Hulme, 2013; Shipstead, Redick, \& Engle, 2012). As such, there is currently no compelling evidence to warrant recommending working memory training within the educational context (Sala \& Gobet, 2017).

This has led researchers to consider other avenues for supporting children with poor working memory, including finding ways to adapt the classroom environment to reduce working memory demands and memory-related failures (Berry, Allen, Mon-
Williams, \& Waterman, 2019; Cowan, 2014; Elliott et al., 2010; Gathercole et al., 2006; Kyttälä, Kanerva, Munter, \& Björn, 2019). However, in order to make the classroom 'working memory friendly', teachers must have a sound understanding of working memory, including its limitations, signs of impairment, and how it impacts upon learning. Whilst poor working memory often cooccurs with other developmental disorders such as ADHD or SLI, it is not itself a specific disorder and, as such, there are fewer resources available to educate teachers about the signs of, and issues related to, poor working memory.

Although not directly exploring teachers' understanding of working memory, several studies have reported that teachers may view children with poor working memory as inattentive or lacking in concentration, rather than recognizing the underlying memory impairment (Gathercole \& Alloway, 2008; Gathercole et al., 2006). To the best of our knowledge, only one study has explicitly explored educational professionals understanding of working memory (Alloway, Doherty-Sneddon, \& Forbes, 2012). In this study, fourteen primary school ${ }^{1}$ teachers completed a semi-structured interview in which they were asked to define working memory, identify signs of poor working memory that might be observed in the classroom, and strategies that might be used to help children with poor working memory. Following the interview, teachers were asked to complete the working memory rating scale (WMRS; Alloway, Gathercole, Kirkwood, \& Elliott, 2008) for children identified as having 'troublesome behaviors' and for age-matched controls. The authors reported that teachers' awareness of working memory was highly variable, with the majority of participants only able to identify one or two signs of impairment, or strategies to help children with poor working memory (although no examples were provided in the paper). When asked to suggest reasons for 'troublesome' behaviors, teachers are described as linking them to personality factors such as having a "quick temper", rather than understanding that these children may have working memory problems (Alloway et al., 2012, pp. 140-141). However, results from the WMRS showed that $65 \%$ of children identified as having 'troublesome behaviors' had scores consistent with poor working memory, in comparison with $17 \%$ of controls. Although this study provides some insights into teachers' understanding of working memory, there are several limitations. Firstly, the sample size $(N=14)$ was very small. Second, only class teachers were recruited, meaning that understanding of other key educational professionals (e.g., teaching assistants, Special Educational Needs Coordinators, ${ }^{2}$ Headteachers) was not explored. Third, data are not provided with regards to how teachers defined working memory, what signs they associated with poor working memory, or what strategies they suggested.

Therefore, there is clearly a need to conduct additional research to improve our understanding of how teachers and educational professionals think about working memory, and of their experiences of poor working memory within the classroom. The results from such research will be important for identifying where misunderstandings, or gaps in knowledge, occur. This can then inform the development of training and resources for those working in schools so that children with poor working memory can be better supported.

The current study therefore aimed to systematically investigate the extent to which educational professionals across the UK understand working memory. We developed a 10-15-min online questionnaire which assessed the extent to which educators were

\footnotetext{
${ }^{1}$ Primary schools in the UK are for children from age 4 years-11 years.

2 Special Educational Needs Coordinators (SENCos) work with children who have a learning disorder or learning difficulties.
} 
able to define working memory, estimate its capacity and duration, identify signs of working memory difficulties, and list strategies to help children with poor working memory. They were also asked whether they believed they had encountered a child with working memory difficulties, signs they observed in these children, and strategies they had applied. Given the lack of any large-scale, systematic research, we did not make any specific predictions about what the findings from the current study would show. However, we did expect to see individual variability in responses, with a range of levels of understanding and experience.

\section{Method}

\subsection{Participants}

One thousand, four hundred and fifty-one respondents completed the questionnaire. Three participants were excluded as they were not a current teacher (e.g. they were retired), 10 were excluded as they did not work in a school (e.g. they worked in a prison), and 13 were excluded as they were not located in the UK. The final analysis was therefore run on data from 1425 respondents. Respondents were evenly distributed across the counties in the UK (see supplementary material (Part A)). The descriptive statistics are presented in Table 1. Participants were recruited through social media (e.g. Twitter, Facebook groups for teachers) and word of mouth. Respondents were entered into a prize draw to win one of three $£ 25$ Amazon vouchers. The study was granted ethical approval by the School of Psychology Ethics Committee at the University of Leeds.

\subsection{Materials and procedure}

A questionnaire was developed to assess understanding of working memory (see Fig. 1 for the structure). This took approximately 10-15 min to complete. Once respondents completed and

Table 1

Respondent demographics. Total $\mathrm{N}$ reflects the number of respondents used to calculate the percentages. Percentages may not add up to $100 \%$ due to rounding.

\begin{tabular}{lll}
\hline Variable & Descriptive statistics & Total N \\
\hline Age - M (SD) & $36.55(\mathrm{SD}=9.73)$ & $1386^{\mathrm{a}}$ \\
Gender - N (\%) & $111(7.87 \%)$ & 1409 \\
Male & $1291(91.63 \%)$ & 1409 \\
Female & $7(0.50 \%)$ & 1409 \\
Prefer not to say & $5.73(\mathrm{SD}=5.84)$ & $1419^{\mathrm{a}}$ \\
Years in current role - M (SD) & $10.71(\mathrm{SD}=7.71)$ & 1419 \\
Years in education sector - M (SD) & $1322(94.03 \%)$ & 1406 \\
Has undergraduate degree - Yes - N (\%) & $874(63.15 \%)$ & 1384 \\
Has postgraduate degree - Yes - N (\%) & & \\
Job role ${ }^{\mathrm{b}}-\mathrm{N}$ (\%) & $1169(82.50 \%)$ & $1417^{\mathrm{d}}$ \\
Classroom teacher & $102(7.20 \%)$ & $1417^{\mathrm{d}}$ \\
Teaching support & $58(4.09 \%)$ & $1417^{\mathrm{d}}$ \\
Special educational needs coordinator & \\
Part of senior leadership team & $84(5.93 \%)$ & $1417^{\mathrm{d}}$ \\
Administrative support & $4(0.28 \%)$ & $1417^{\mathrm{d}}$ \\
Type of school ${ }^{\mathrm{b}}$ - N (\%) & & \\
Primary (4-11 years) & $907(64.46 \%)$ & $1407^{\mathrm{d}}$ \\
Secondary (11-16 years) & $419(29.78 \%)$ & $1407^{\mathrm{d}}$ \\
Primary and secondary school (4-16 years) & $81(5.76 \%)$ & $1407^{\mathrm{d}}$ \\
\hline
\end{tabular}

Note: $\mathrm{M}=$ Mean, $\mathrm{SD}=$ Standard deviation, $\mathrm{N}=$ Number of participants.

a After removing participants who did not respond or whose response clearly included a typing error. These respondents were removed from the demographic calculation but retained for the main analyses.

b See supplementary material (Part B) for further details on how the responses to this question were categorized.

c Or similar role (e.g. "head of children's development").

d After removing participants who did not provide a response or whose response could not be categorized.

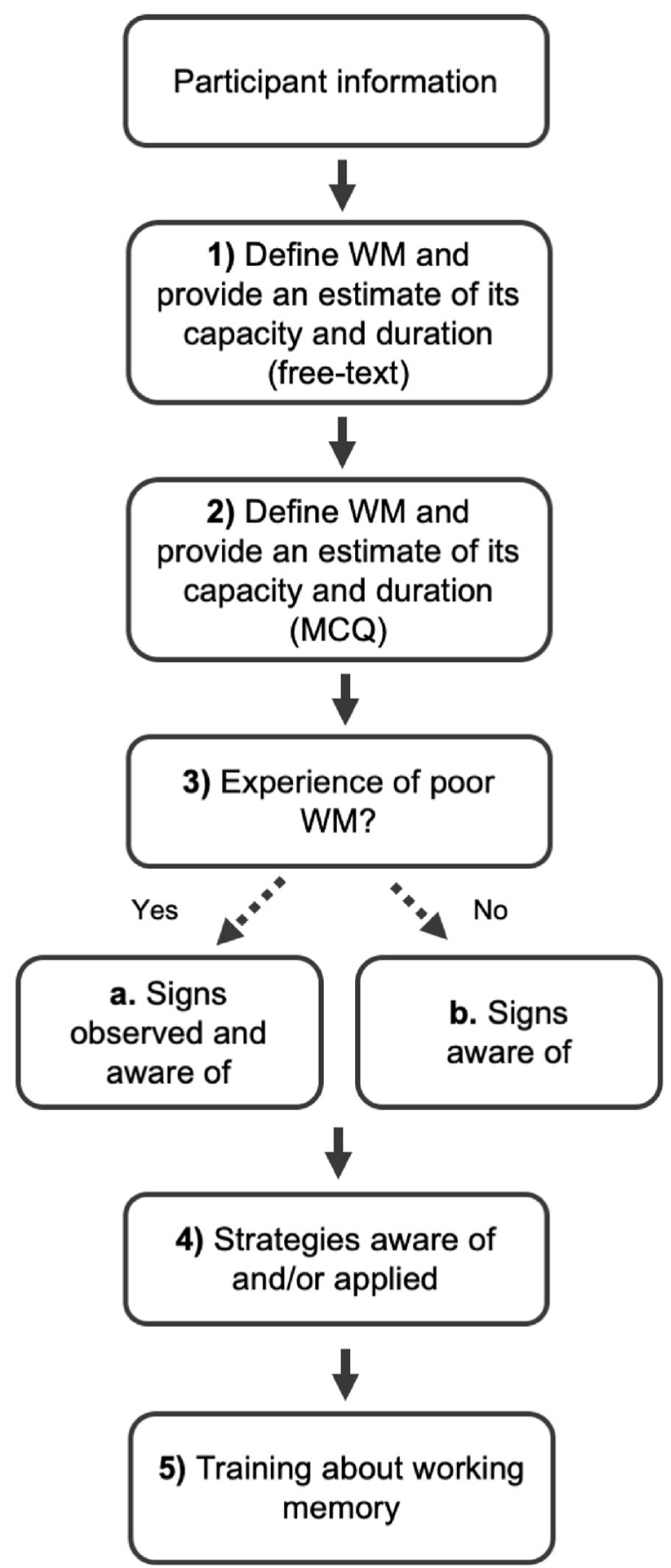

Fig. 1. The structure of the questionnaire. The rectangular boxes denote sections of the questionnaire. Some of the sections were separated onto several pages. Acronyms: $\mathrm{WM}=$ working memory, $\mathrm{MCQ}=$ multiple-choice question.

saved a page, and moved onto the next page, they could not return to the previous page. This was to ensure that participants could not use information from later parts of the questionnaire to go back and change their earlier responses. A copy of the questionnaire can be downloaded from the Open Science Framework (OSF) page (https://osf.io/638dw/).

Firstly, participants were asked to provide some personal information, including their gender, date of birth, years in their current role, years in the education sector in general, and their educational qualifications. 
After providing their personal information, respondents completed the main body of the questionnaire:

\section{Definition, Duration, and Capacity Free-Text Questions}

Respondents were asked to give free-text responses regarding the definition of working memory, an estimate of its capacity, and an estimate of its duration. As children's working memory changes with age throughout the school years (Gathercole, Pickering, Ambridge, \& Wearing, 2004a) and considerably more research has investigated the limits of working memory in adults, respondents were asked to base their judgements on adults' working memory. In addition, given that the duration and capacity of working memory is affected by strategy use (such as verbal rehearsal), we explicitly instructed respondents to consider the duration and capacity when such strategies are not utilized. Immediately after each question, participants were asked to give a confidence judgement on a Likert scale from 1 to 5 (where $1=$ not at all confident and $5=$ very confident).

\section{Definition, Duration, and Capacity Multiple-Choice Questions}

On the next page, participants were asked multiple-choice versions of the same questions (definition; capacity; duration). Given that the options for the multiple-choice questions contained the 'correct' answers, we prevented respondents from navigating back to the free-text questions to ensure that they could not change their original, uncued, responses. The questions and multiplechoice answers are displayed in Table 2. For the definition question, the correct answer (i.e., the option that described working memory) was written to be consistent with any of the major theories of working memory (e.g., the multicomponent model (Baddeley, Hitch, \& Allen, 2021; Baddeley, 2012); the embedded process model (Cowan, 1999; Cowan, Morey, \& Naveh-Benjamin, 2021); the TBRS (Barrouillet \& Camos, 2015, 2021). The lures consisted of definitions of episodic memory, semantic memory, procedural memory, and prospective memory. For the capacity question, we defined the correct answer as 2-9 items. We chose this range because we wanted to credit respondents for being aware that working memory capacity is limited but did not want to constrain them to any particular model or theory, or penalize them if they were aware of the well-known short-term memory limit of seven plus or minus two items (Miller, 1956). For the duration question, we defined the correct answer as "a few seconds", which is consistent with all the major models of working memory. As with the free-text responses, participants were asked to give a confidence judgement after providing each of their responses (on the same $1-5$ Likert scale).

3. Experience of Children with Working Memory Impairments and Knowledge About Signs Associated with Poor Working Memory

Respondents were asked if they believed they had experience of children with poor working memory. The questions that followed depended on their response to this question. If participants responded yes, they were asked about associated signs. This was asked as a two-part question. Firstly, participants were asked what signs indicative of poor working memory they had observed in these children, and second, what other signs they thought might also be associated with working memory impairments. If respondents believed they had not experienced a child with poor working memory, the first part of the question was omitted, and they were simply asked what signs they thought might be associated with poor working memory. The signs stated by respondents who did not believe they had experienced a child with poor working memory are not presented in the main text but can be found in the supplementary material (Part C).

\section{Awareness of, and Application of, Strategies to Support Children with Poor Working Memory}

The rest of the questionnaire was the same for all respondents. As part of this section, respondents were first asked what percentage of children they believe have working memory difficulties severe enough to affect their academic achievement (see supplementary material for the results; Part D). Next, respondents were asked which strategies they were aware of to help support children with poor working memory, and which (if any) they had implemented themselves.

\section{Training About Working Memory}

Finally, respondents were asked if they had received training about working memory as part of their studies (e.g. a degree), training as part of their role (e.g. during a teacher training day), or both. At the end of the questionnaire, they were also whether they

Table 2

The multiple-choice questions asked and possible answers. The correct answers are in bold. Italicized information in square brackets was not presented to respondents.

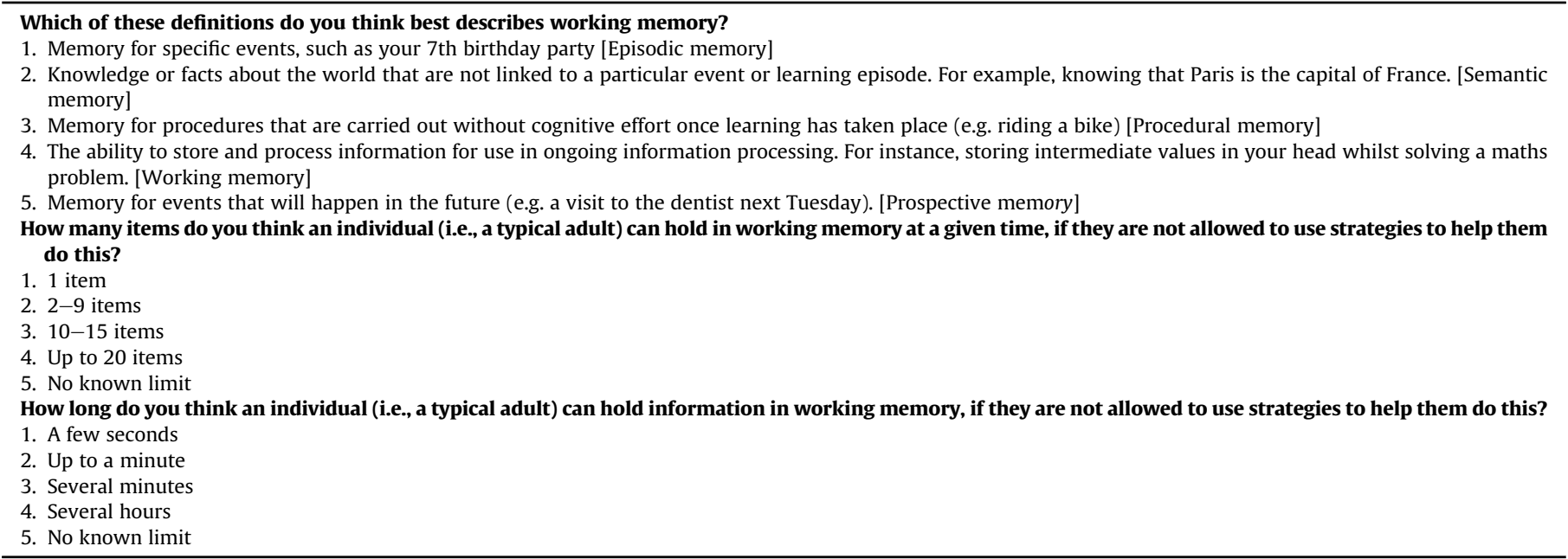


desired more training (either in person or online: yes/no).

\subsection{Scoring and data analysis}

\subsubsection{Free-text responses}

When analyzing the data from the free-text responses, categories were created for each question. For the duration and capacity questions, the categories were chosen to match the multiple-choice question options as much as possible (further details are presented in the Results section). For the other questions (definition of working memory, signs of working memory impairment, and strategies to help children with poor working memory), processing the responses involved several stages. Firstly, one of the authors read all of the responses and created categories based on the responses. For example, for the question asking about signs of poor working memory, categories were created to reflect signs frequently reported (e.g. "poor retention", "short attention span", "behavior problems"). Categories for each question were then discussed with the other authors, with any amendments made as necessary. Then, for each question a subset of 100 responses was independently categorized by the other authors (i.e., for each question the same 100 responses were categorized by the other authors). For all question types (definition, signs, strategies), the agreement rate between the primary scorer and each of the other two scorers was $\geq 90 \%$. Where there was disagreement between the authors, this was resolved by discussion. Further details on the categorization of the free-text responses is given in the relevant sections of the Results, to aid interpretation. As respondents often listed several characteristics of working memory (definition question) or several signs/strategies, each response could be scored as stating multiple categories. The frequency and percentage of respondents who listed each category are reported, and percentages were calculated including only participants who provided a response to that question. For the signs and strategies questions, we also calculated the number of categories identified by respondents.

For most of the free-text questions, the vast majority of respondents provided an answer. Only 3\% did not provide a response for the free-text definition question. Further, most of the respondents who had experienced a child with poor working memory answered both questions concerning signs of working memory impairment (e.g. around a 2-3\% non-response rate). For those who did not believe they had experienced a child with poor working memory, the non-response rate was higher for the signs question (11\%). The percentage of participants who did not provide a response was relatively higher for the questions assessing strategies (around 20\% for total strategies, 43\% for strategies applied).

Clearly some caution is required when categorizing or scoring free-text responses as they do not always fit clearly into categories and some subjectivity is inevitably involved, particularly given the wide variety of responses generated. We acknowledge this issue and have made the raw data freely available on the Open Science Framework (OSF) to improve transparency (https://osf.io/638dw/).

\subsubsection{Multiple-choice questions}

For all multiple-choice questions, the frequency and percentage of participants who gave each response is presented. The percentage was calculated including only participants who provided a response to that particular question.

\section{Results}

1. Definition, Duration, and Capacity Free-Text Questions

\subsection{Definition}

Categories were created to reflect common features reported by respondents. For example, many responses made reference to the fact that working memory involved holding on to information over short periods of time or involved short-term memory. Another common feature was to reference processing of information to complete a current task. Some responses defined other types of memory, for example, prospective memory, or long-term memory ("The ability to retain information over a long period of time, e.g. recall facts and knowledge acquired over a series of lessons to attain on a test"). Several responses were difficult to classify as they gave vague or ambiguous statements ("Part of the brain responsible for holding info regarding decision making") and were classified as "unclear memory type". Descriptions of each definition category, and examples of responses that would fit within each category are presented in the supplementary material (Part E).

Responses varied considerably in length (Mean number of words: 15.5 , Standard deviation $(S D)=11.9$, Range $=0-139$ ). Some respondents only stated one characteristic (e.g., "short-term memory"), whilst others wrote several sentences. For the latter, each item of information within the response was categorized separately. For example, "Working memory is the part of our brain that allows us to think about something and temporarily hold information - repeatedly holding things in this part of the memory will allow information to be passed to the long term memory", would be categorized as 'short-term memory' and 'correct links with LTM'. Further, several participants wrote statements that contained both correct and incorrect information (e.g. "How memory retains info short/long term"), or contained both correct and ambiguous information (e.g., "Part of the brain storing temporary information. Day to day related". Therefore, the total number of items of information provided $(N=2434)$ was higher than the total number of respondents who provided an answer to this question $(N=1382)$.

Fig. 2A displays the different categories created for this question, along with the number and percentage of respondents who provided an answer containing a component from each of these categories. Categories in dark gray relate to items of information that were essentially "correct" in that they referred to features that are characteristic of working memory (e.g., limited capacity; explained correctly how working memory links to LTM). Categories in midgray relate to items of information that were ambiguous, either because they could apply to other types of memory as well as to working memory (e.g., related to decision-making), or because they were not characteristics typically used to define working memory (e.g., it can be recalled quickly), but were not incorrect per se. Categories in light-gray relate to items of information that were incorrect because they referred to characteristics that are associated with other types of memory (e.g., memory held over the longterm).

With regard to the category of "short-term memory", we appreciate that the terms "working memory" and "short-term memory" are not always used synonymously in the research literature. Short-term memory is sometimes described as primarily describing storage, whilst working memory is thought to reflect additional involvement from executive processes, although some theoretical models include both storage and executive processes within the broader framework of working memory (see Cowan, 2017). However, the purpose of this survey was not to see if educational professionals were aware of differences in definitions between theoretical models, but to ascertain whether they broadly understood the key aspects of a limited capacity system operating over short timescales that is crucial for learning. The short-term memory category was therefore classified as correct. 

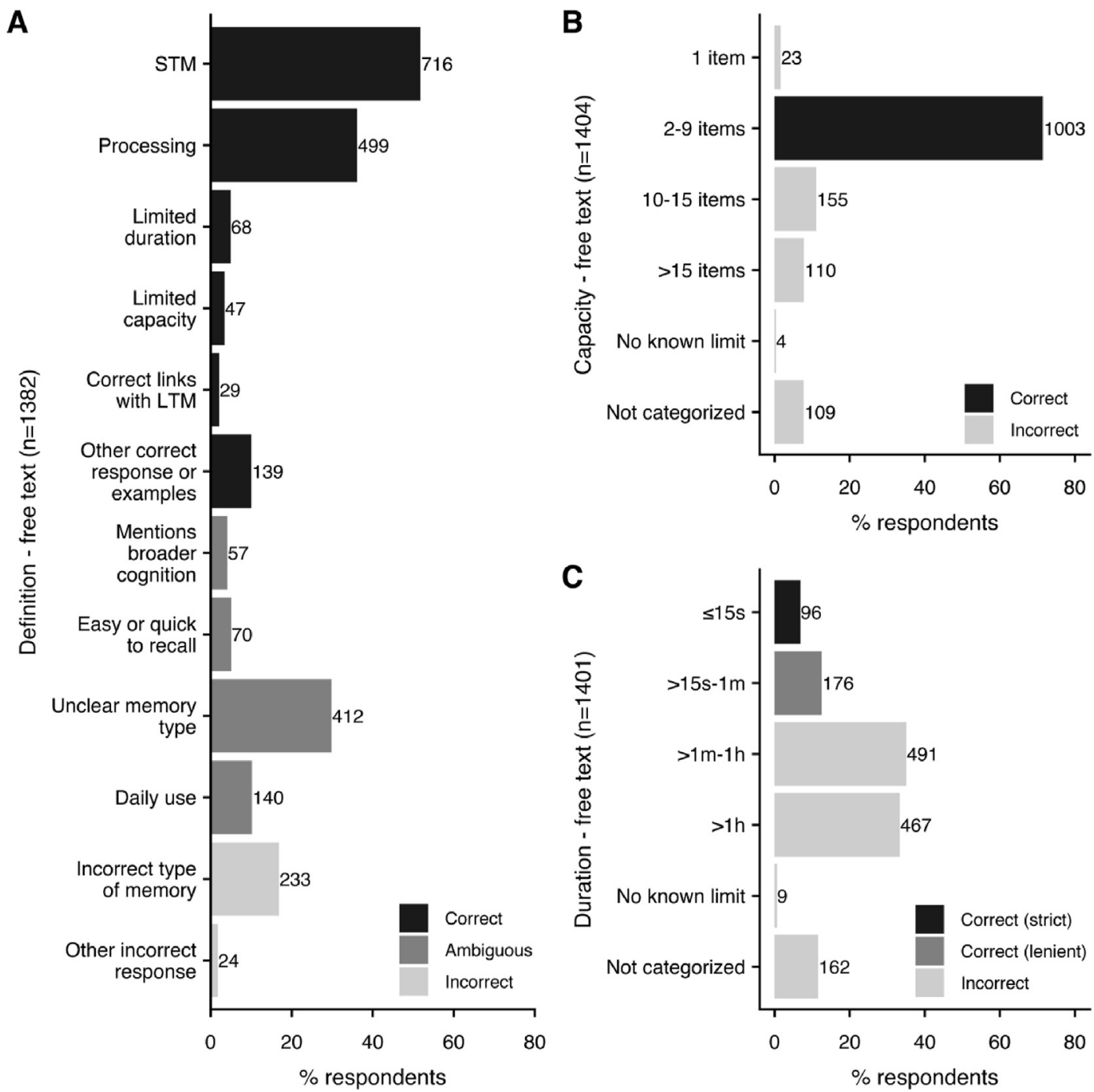

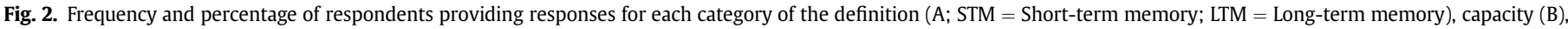

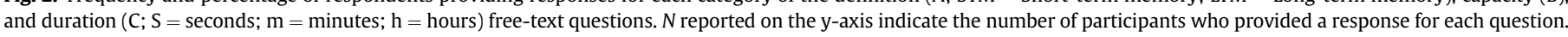

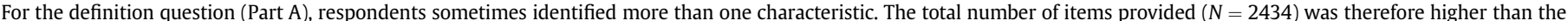
number of participants who gave a response $(N=1382)$.

\subsection{Capacity}

The categories were based on the multiple-choice question options (see Table 3 in the Method section); "1 item", "2-9 items", “10-15 items", “>15 items", "No known limit", and "Not categorized". Answers were scored as "Not categorized" if participants did not provide a numerical estimate as directed (e.g. "Depends on the person") or they did not answer the question correctly (e.g. they provided a duration estimate; " 1 week"). Responses were recorded as "no known limit" if they indicated that they did not believe there was a limit to the number of items that could be held (e.g. "Unlimited", "Infinite"). If participants gave a range of values that

Table 3

The number (and percentage) of respondents who answered zero, one, two, and three of the multiple-choice questions correctly $(N=1420)$. Percentages may not add up to $100 \%$ due to rounding.

\begin{tabular}{lllll}
\hline & Zero & One & Two & Three \\
\hline Strict scoring & $69(4.9 \%)$ & $372(26.2 \%)$ & $826(58.2 \%)$ & $153(10.8 \%)$ \\
Lenient scoring & $66(4.7 \%)$ & $330(23.2 \%)$ & $658(46.3 \%)$ & $366(25.8 \%)$ \\
\hline
\end{tabular}

covered two response categories (e.g. 6-10 items), the response was categorized based on the median value within the range. The frequency of responses per category are displayed in Fig. 2B. The majority of participants gave the correct answer (1003 respondents; $71.4 \%$ ).

\subsection{Duration}

As with the capacity question, the free-text scoring was based on the multiple-choice question options. Given the first (correct) option in the multiple-choice question was "a few seconds", we had to define a numerical cut-off to create the equivalent category. Similarly, we had to create numerical cut-offs for the equivalent of "several minutes" and "several hours". The following categories were used: " $\leq 15 \mathrm{~s}$ " (equivalent to the "several seconds" multiplechoice question option), "> $>15 \mathrm{~s}-1 \mathrm{~min}$ " (equivalent to the "up to 1 min' multiple-choice question option), "> 1 min -1 h" (equivalent to the "several minutes" option), " $>1 \mathrm{~h}$ " (broadly equivalent to the "several hours" option, but includes all responses greater than $1 \mathrm{~h}$ ), "No known limit", and "Not categorized". Responses were recorded as "No known limit" if they suggested there was no limit to the 
amount of time information could be held (e.g. "Forever", "Indefinitely"). Answers were categorized as "Not categorized" if participants did not provide a numerical estimate (e.g. "not long"), or did not provide a timescale (e.g. "15-20", "3 items"). Where participants responded "seconds", this was categorized as up to $15 \mathrm{~s}$. The frequency of responses per category is displayed in Fig. 2C.

Clearly, responses could be placed in different bins (e.g., 1-10 min; 11-60 min). However, the key distinction here is between answers given in units of seconds, and those given in any other units. The number of participants who gave responses in seconds (" $\leq 15 \mathrm{~s}$ and ">15 s-1 min") was 272 (19.4\%). If we take a stricter approach to the scoring and look at the number of participants in the category "up to $15 \mathrm{~s}$ " (which would more closely match most models of working memory), this drops to 96 (6.9\%).

\section{Definition, Duration, and Capacity Multiple-Choice Questions}

Fig. 3 displays the frequency and percentage for each answer for the definition, capacity and duration multiple-choice questions. Percentages were calculated excluding participants who did not select an answer. The most commonly selected response for the definition multiple-choice question was the correct answer describing working memory. This was selected by 1257 participants (88.3\%), which was significantly higher than the guessing rate of $20 \%(t(1422)=80.3, p<.001$, Cohen's $d=2.13)$. Similarly, for the capacity multiple-choice question, the most commonly selected response was the correct answer (2-9 items; 1059 respondents; 74.5\%). This was significantly higher than the chance guessing rate $(20 \% ;(t(1420)=47.2, p<.001$, Cohen's $d=1.3)$. However, for the duration question, the correct answer (a few seconds) was only selected by a minority of respondents (171 respondents; $12.0 \%$ ), with the remainder of the participants overestimating the amount of time information can be held. This was significantly lower than chance $(20 \% ;(t(1422)=-9.3, p<.001$, Cohen's $d=-0.2)$. However, one possibility is that the low number of correct responses to this question might have resulted from participants being confused by
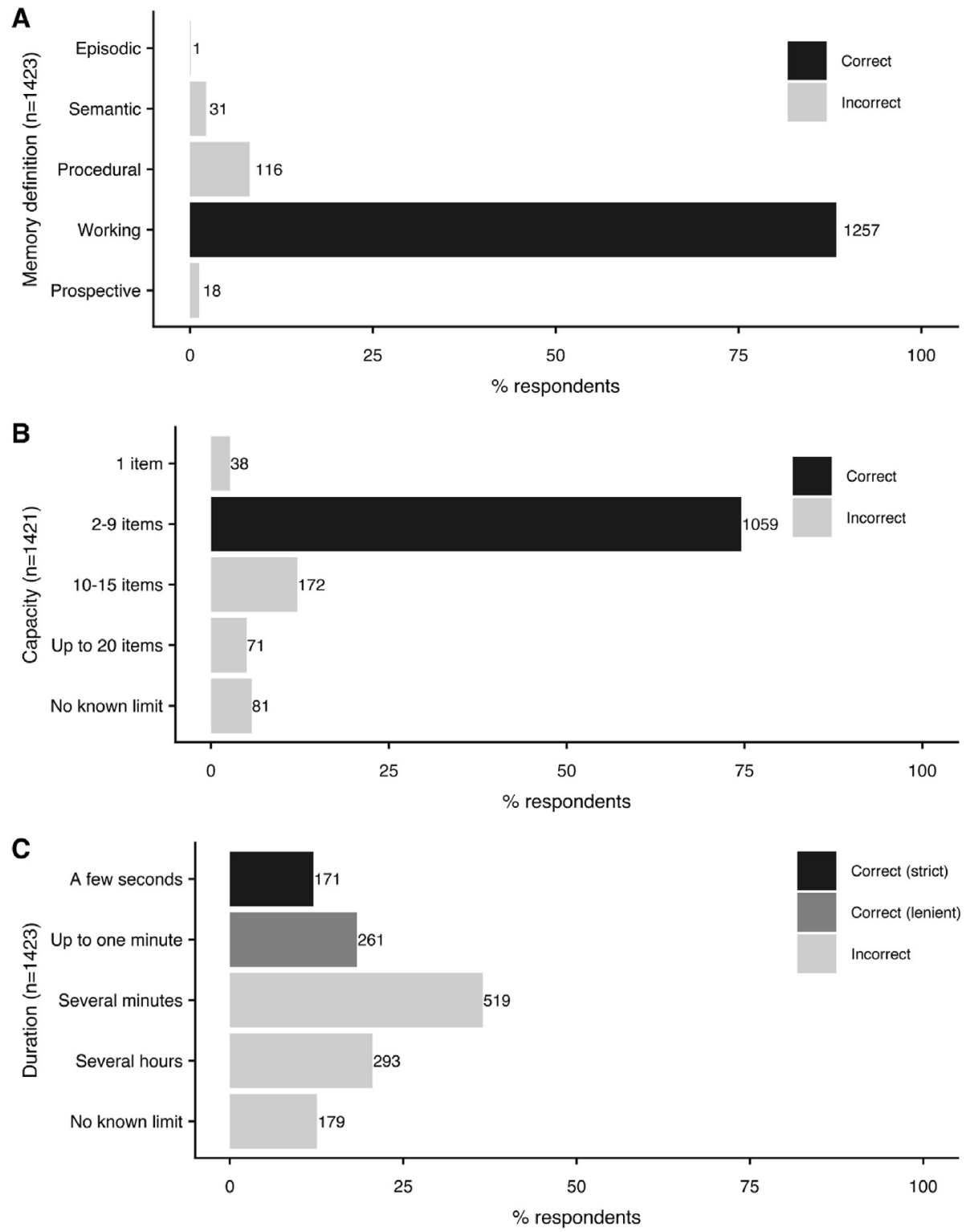

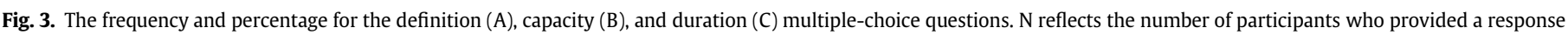

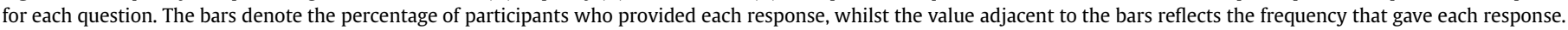


the "a few seconds" and "up to a minute" responses, which could be viewed as overlapping. If the question is scored leniently, with both "a few seconds" and "up to a minute" classified as correct, 432 respondents $(30.4 \%)$ responded correctly. Whilst fewer than onethird of participants selected the correct answer even with lenient scoring, this was significantly higher than chance $(t(1422)=8.5, p<.001$, Cohen's $d=0.2)$.

Further analysis was completed to investigate how many respondents answered all three of the multiple-choice questions correctly. This was calculated using both the strict duration scoring (i.e. where "several seconds" was the only correct answer), and the lenient duration scoring (i.e. where "several seconds" and "up to $1 \mathrm{~min}$ " were both scored as correct). Five individuals were excluded from this analysis for not providing an answer to all three questions $(N=1420)$. The number and percentage of respondents answering zero, one, two, or three of the questions correctly is displayed in Table 3.

\section{Experience of Children with Working Memory Impairments and Signs of Working Memory Impairment}

Within this section, respondents were first asked whether they believed they had experience of a child with poor working memory. 1423 respondents answered this question, with 1379 (96.9\%) reporting that they did have experience with a child/children with poor working memory. Participants who believed they had experienced a child with poor working memory were then asked what signs they had observed and what other signs they believe may be associated with poor working memory. Those who did not believe they had experienced a child with poor working memory were asked only the latter question. From the responses given, categories were formed that reflected signs commonly reported (see Fig. 4). Descriptions of each sign category, and examples of responses that would fit within each category are presented in the supplementary material (Part F). Some statements were classified as reflecting more than one category. For instance, if a response stated "forgets instructions", this was categorized as evidence of "poor retention" and "difficulties with instructions, steps or routines".

The analyses exploring signs reported by respondents who had not experienced a child with poor working memory is presented in the supplementary material (Part C). For the respondents who believed they had experienced a child with poor working memory, the two questions (signs observed and other signs aware of) were combined (referred to as "total signs" hereafter). This is reported below alongside analyses examining responses to the signs observed question only. Participants were excluded if their responses to either question made it clear they were identifying signs broadly associated with developmental disorders (e.g. "Behaviours (nb am talking about children with brain disorders and damage)" rather than working memory difficulties. This resulted in the exclusion of six respondents. Participants who did not provide a response or who did not list any signs (e.g. "not sure") were also excluded from the analysis ( $N=30$ for total signs and $N=35$ for signs observed). The analyses therefore included 1343 participants for total signs and 1338 participants for signs observed.

Fig. 4 shows the frequency and percentage of participants who listed each sign. The most frequently listed categories for both analyses (total signs and signs observed) were: poor retention (e.g. "Inability to recall information immediately after discovering it", "Not being able to hold an answer in their heads while working something else out"), difficulties with instructions, steps or routines ("Find it hard to understand spoken instructions when not given one at a time"), difficulties with classroom/learning activities ("Poor academic achievements e.g. reading"), and short attention span ("getting easily distracted", "gazing around").

Further analysis was conducted to investigate the number of signs each participant reported (see Fig. 5A). For this analysis, respondents who reported no signs were included. The sample size for both analyses (total signs and signs observed) was therefore 1373. The mean number of total signs was $3.7(S D=1.6$; Range $=0-10$ ), whilst the mean number of signs observed was 2.4 $(S D=1.3$; Range $=0-8)$. The vast majority of respondents listed at least one sign (1343 (97.8\%) for total signs; 1338 (97.5\%) for signs observed). Approximately $29 \%$ of respondents listed five or more total signs (394; $28.7 \%$ ), although only approximately $6 \%$ reported having observed more than five signs ( $87 ; 6.3 \%)$. Finally, analyses were conducted to examine whether the number of signs reported was associated with the number of MCQs answered correctly (see supplementary material (Part $\mathrm{H})$ ).

\section{Awareness of, and Application of, Strategies to Support Children with Poor Working Memory}

Respondents were asked whether they knew of any strategies that could be used to help children with poor working memory and which of these strategies (if any) they had applied. As with the signs analyses, the categories were formed based on participants' responses. Descriptions of each strategy category, and examples of responses that would fit within each category are presented in the supplementary material (Part G). Participants sometimes reported applying strategies they had not included in their response to the initial question asking what strategies they were aware of. Therefore, responses to these two questions were combined to give the total number of strategies mentioned by respondents (referred to as "total strategies" hereafter). This is reported below, alongside analysis exploring strategies respondents reported having applied themselves (see Fig. 6).

Eighteen participants were excluded from both analyses for discussing approaches used to support broader special educational needs (e.g. "Worked with a child with FASD [Fetal alcohol syndrome disorders] and another with speech and language difficulties. Different strategies work with different children. Some prefer audio help (recording their own voice) others need visual stimuli or written material. Prompting/clues to support too") or children they interact with outside of school settings (e.g. "My niece has working memory problems she uses the step ladder where she will walk the man up a ladder with her fingers when trying to spell.") in at least one of their answers. Respondents who did not list any strategies were also removed $(N=284$ for total strategies, $N=603$ for strategies applied). The number of participants in each analysis was therefore 1123 for total strategies and 804 for strategies applied.

By far, the most commonly reported strategy that respondents had applied was physical or visual mnemonic aids ("Use pictorial prompts, working walls, whiteboards", "Visual pics to support instructions", "Symbol cards for each stage of instructions"). This was also the most commonly listed category in the total strategies analysis. The other strategies most frequently applied were the use of specific strategies within learning activities (e.g. "Metacognitive strategies e.g. mnemonics", "Using visual prompts"), simplification of information (e.g. "Small steps to follow", "More precise, simpler instructions") and writing things down ("Writing down tasks on board or in sheets", "Giving instructions as checklists and encouraging their own note making"). 


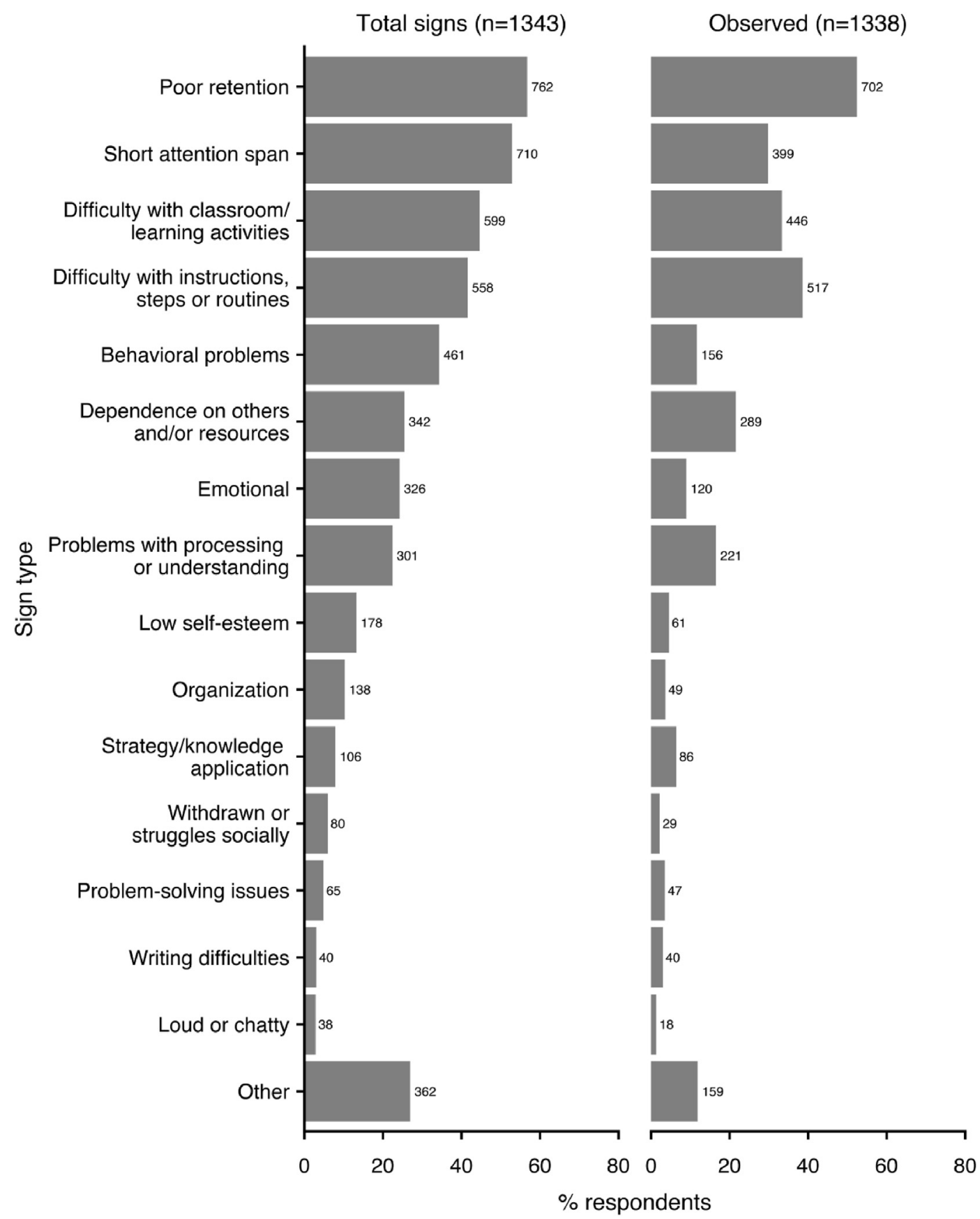

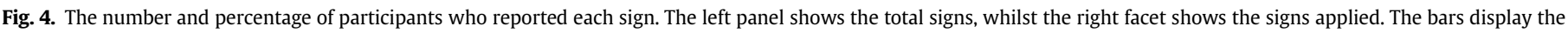

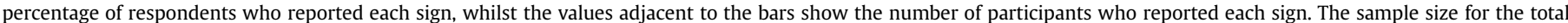

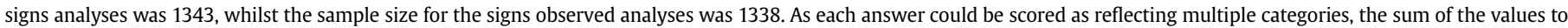
the right of the bars exceeds the total number of participants included in the analyses.

Further analysis was conducted to examine the total number of strategies and the number of strategies applied (see Fig. 5B). Respondents who did not report any strategies were included in these analyses ( $N=1407$ for both total strategies, and strategies applied). The mean number of total strategies was $2.5(S D=1.9$; Range $=0-9$ ), meanwhile the mean number of strategies applied was $1.3(S D=1.5$; Range $=0-8)$. Caution should be taken when interpreting this analysis, as not all strategies reported by participants have a good evidence base (e.g. working memory training [e.g. Melby-Lervåg \& Hulme, 2013; Shipstead et al., 2012], learning styles [e.g. Kirschner, 2017; Pashler, McDaniel, Rohrer, \& Bjork,
2008]. Examination of Fig. 5B reveals large individual differences in the number of strategies reported. A considerable number of respondents reported zero strategies in total $(284 ; 20.2 \%)$, with even more respondents not listing any strategies for the applied question $(603 ; 42.9 \%)$. Fifteen percent of participants reported more than five strategies in total (211 respondents), although less than $4 \%$ had applied more than five signs (51 respondents; 3.6\%). Finally, as with the signs, analyses were conducted to investigate whether the number of strategies reported was associated with the number of MCQs answered correctly. The outcomes are presented in the supplementary material (Part H). 
A

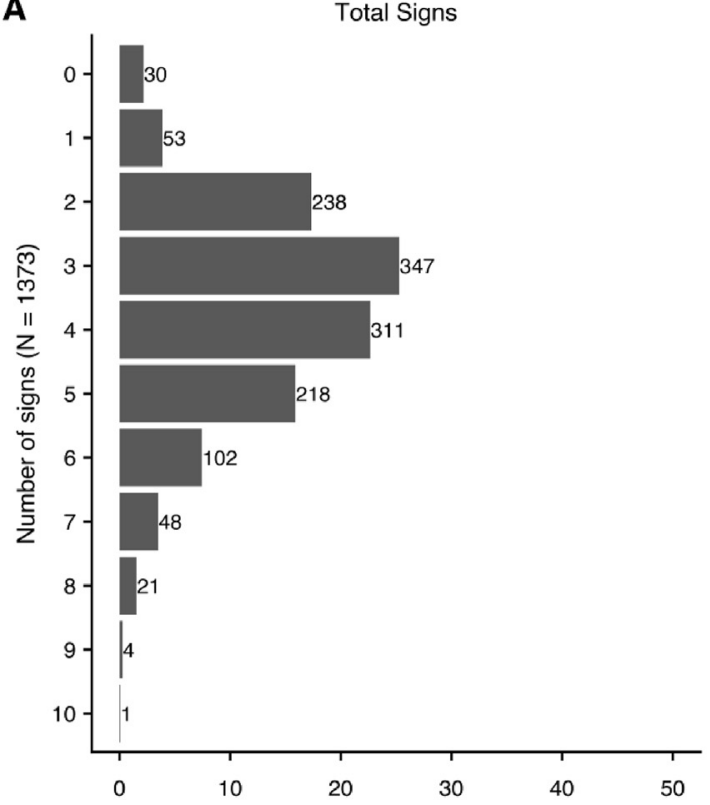

Signs Observed

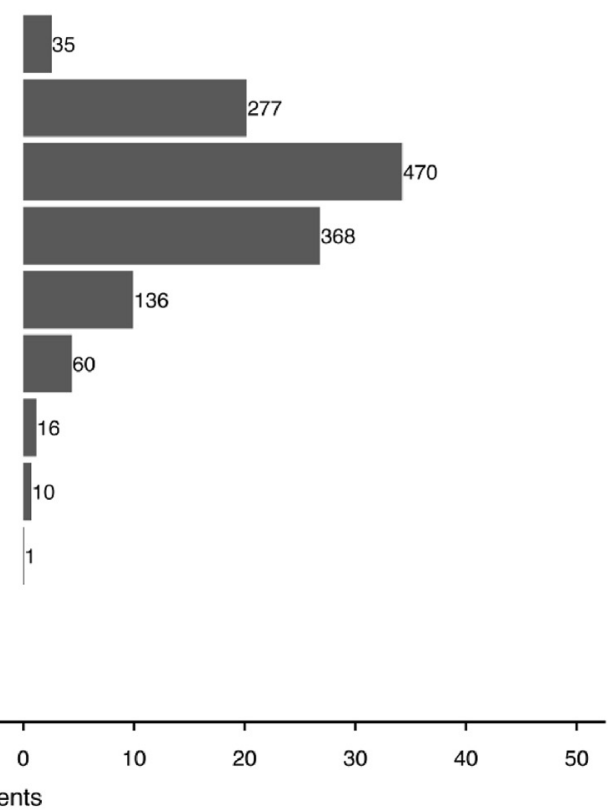

B

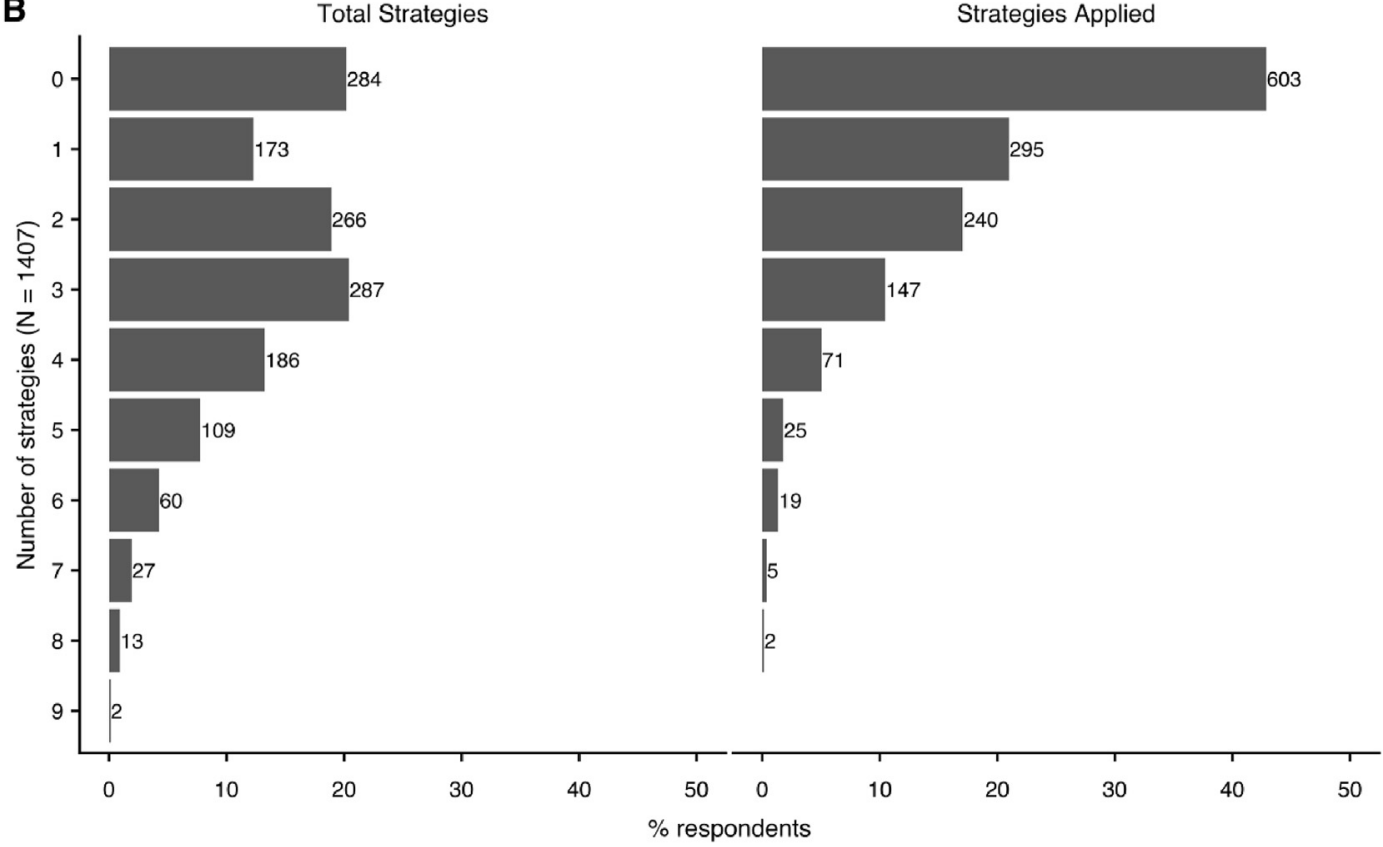

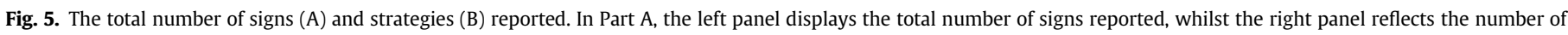

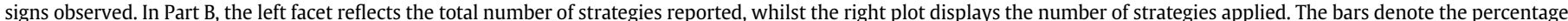

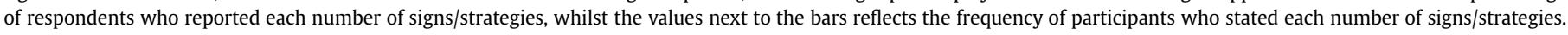
$N=1373$ for signs (Part A) and $N=1407$ for strategies (Part B).

\section{Training About Working Memory}

\subsection{Past training}

Respondents were asked whether they had received training on working memory, either during their time working in the education sector $(N=1423)$ or during their studies $(N=1411)$. Only 226 respondents $(15.9 \%)$ had received training during their time in the education sector, and 171 (12.1\%) had received training during their studies. When considering these questions together, $25.3 \%$ had received some training on working memory (357 of the 1410 respondents who answered both questions). Where individuals had reported receiving training, this was often brief in nature (e.g. "Part of a general SEND lecture", "Brief information in a general barriers to learning lecture") or part of another degree program as opposed to their teaching training (e.g. "Part of psychology degree", "Studying memory as a module during psychology degree").

\subsection{Further training}

Finally, at the end of the questionnaire, respondents were asked 
Total strategies $(n=1123)$

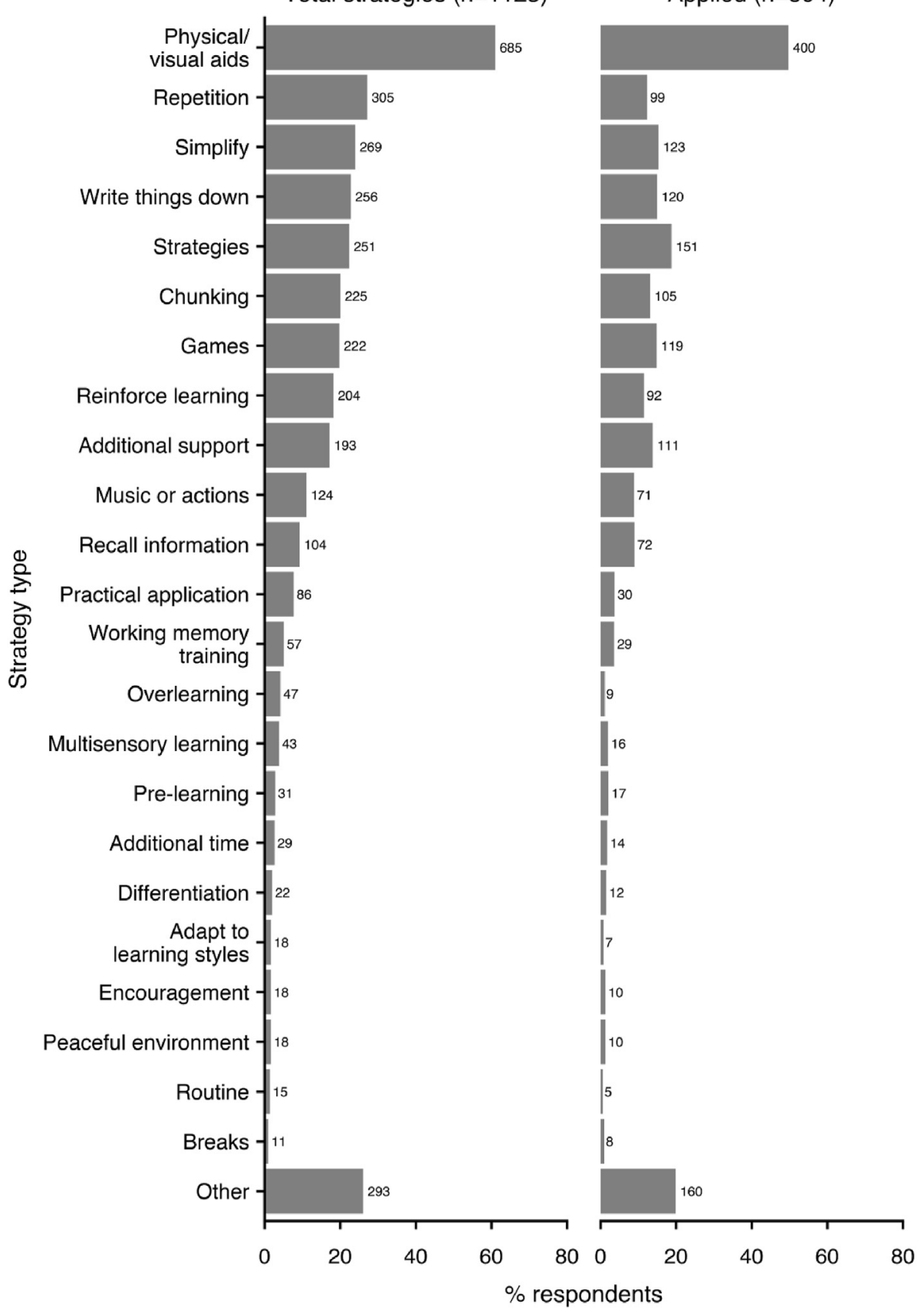

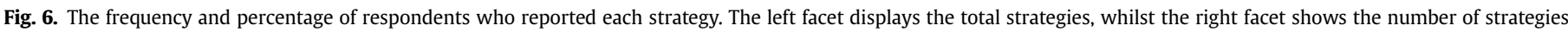

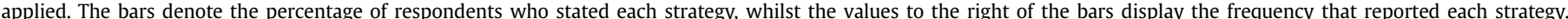

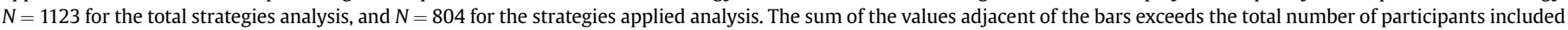
in the analyses as each response could be scored as reflecting multiple categories.

Table 4

The frequency (percentage) each response (yes/maybe/no) was selected for the questions assessing participants' desire for further face-to-face and online training. Percentages may not add to $100 \%$ due to rounding.

\begin{tabular}{lll}
\hline & Face-to-face $(\mathrm{N}=1425)$ & Online $(\mathrm{N}=1425)$ \\
\hline Yes & $857(60.1 \%)$ & $1236(86.7 \%)$ \\
Maybe & $413(29.0 \%)$ & $147(10.3 \%)$ \\
No & $155(10.9 \%)$ & $42(2.9 \%)$ \\
\hline
\end{tabular}

whether they would like further training about working memory, either face-to-face or online (yes/maybe/no; $N=1425$ for both). The outcomes are presented in Table 4 . The majority of respondents indicated they would be interested in further training on working memory, with 1236 participants (86.7\%) stating they would be interested in online training and 857 participants (60.1\%) indicating they would be interested in face-to-face training. When considering the responses to both questions, 1277 respondents $(89.6 \%)$ indicated they would be interested in some form of training (i.e. online or face-to-face) and 816 respondents (57.3\%) expressed interest in both forms. Only 29 respondents $(2.0 \%)$ stated they would 
not be interested in either form of training.

\section{Discussion}

The current study aimed to examine how teachers and other educational professionals understand the construct of working memory. An online questionnaire was developed, in which respondents were asked: (i) to define working memory, and estimate its capacity and its duration (assessed using both free-text and multiple-choice questions); (ii) whether they believed they had experienced a child with poor working memory; (iii) to list signs of poor working memory of which they were aware, or which they had observed; (iv) to indicate strategies they were aware of that could help children with poor working memory, and ones that they had applied; and (v) whether they would like more training about working memory.

The data collected from 1425 respondents indicated that the majority of educational professionals (88.3\%) could select the correct definition of working memory when the alternatives were descriptions of other types of memory (e.g., episodic memory, prospective memory), but when asked to provide a free-text definition, there was a wide variety of responses reflecting less secure understanding. With regards to working memory capacity, over $70 \%$ of respondents (both free-text and to the multiple-choice questions) correctly identified that working memory has a limited capacity of only a few items. However, most respondents overestimated the duration with which information could be held (approximately 70\% for the multiple-choice question, $80 \%$ for the free-text question), with this increasing further when stricter scoring was used (around 90\% for both question types). When considering the multiple-choice questions together, approximately one quarter of respondents answered all three questions correctly, with this reducing to approximately $10 \%$ when stricter scoring was used for the duration question. Almost all of the respondents said they had experienced a child with poor working memory (96.9\%), with most of these able to list at least two signs of working memory difficulties (94.0\%). Fewer individuals were aware of strategies to help individuals, although around two-thirds of participants listed at least two. There was, however, considerable variation in both the number of signs and strategies identified across respondents. Only around one-quarter of respondents had received some sort of training about working memory, with nearly $90 \%$ of respondents reporting they would like further training.

The existing literature on teachers' knowledge relating to working memory has suggested that this group have relatively limited understanding of the concept, and that some may believe children with poor working memory are simply inattentive or lacking in focus (Alloway et al., 2012; Gathercole \& Alloway, 2008). However, only one study had explicitly investigated teacher's understanding of working memory (Alloway et al., 2012), and that was with a very small sample $(N=14)$. The current study shows a more complex and mixed picture, with some aspects of working memory relatively well understood (e.g., capacity) and some misunderstood (e.g., duration limits). The belief that information can be held in working memory for several minutes, or even hours, without the use of overt rehearsal or other strategies, may have implications for how teachers provide support to children with poor working memory in the classroom. For example, teachers may not realize how quickly information can be lost from working memory, which may contribute to the misperception that failure to complete a task is due to lack of concentration rather than due to inability to retain the relevant information in mind over the required timescale.

With regards to free-text definitions of working memory, there was evidence of wide individual differences, both in terms of how much respondents wrote, as well as the content of their responses.
The most commonly reported feature of WM (just over one half of respondents) was to state that it involved storage of information over the short-term. The next most common (over one-third of respondents) was to indicate that WM was related to processing of information. Other correct features mentioned by respondents included limited capacity or limited duration, although each of these categories were identified by fewer than $10 \%$ of respondents. Other correct examples (e.g., "In numeracy you would use the components of information to complete a mental calculation", "hold set of instructions in head then follow", "holding a phone number in your mind", "it helps when copying down from the board") were provided by approximately $10 \%$ of participants. A significant number of responses contained ambiguous or vague information, with nearly $30 \%$ of participants providing information that was unclear with regards to what memory it could refer to ("a person's ability to retain information", "what you can remember to solve problems", "your memory in day-to-day activities"). Finally, nearly $17 \%$ of respondents gave information that incorrectly referred to a different type of memory ("remembering what you had for lunch yesterday", "what we can store in long term memory that we can access later", "is how much you remember at work"). Further, some participants gave definitions that contained both correct and incorrect information, or correct and ambiguous information. Overall, the free-text definitions reflected a wide range in participants' understanding of WM and suggest that further training for teachers on the exact nature of WM would be beneficial.

The total number of signs reported ranged from 0 to 10 , with those listed broadly in line with signs of impairment reported by working memory research. For instance, many of the signs that respondents most commonly reported (i.e. poor retention, short attention span, difficulty following instructions) have been highlighted as characteristics of impairment in both journal articles (Alloway et al., 2012; Gathercole, Pickering, Knight, \& Stegmann, 2004b) and publications aimed at teachers (Gathercole \& Alloway, 2008). For example, several studies have investigated the link between working memory and following instructions with particular reference to its importance in the classroom (Baddeley, Hitch, \& Allen, 2021; Gathercole, Durling, Evans, Jeffcock, \& Stone, 2008; Jaroslawska, Gathercole, Logie, \& Holmes, 2016; Waterman et al., 2017; Yang et al., 2021; Yang, Allen, Holmes, \& Chan, 2017). Indeed, when only looking at signs actually observed, difficulty with following instructions (or steps/routines) was the second most frequently reported sign, behind poor retention. Some interesting patterns emerge when considering the total number of signs reported, compared with signs actually observed. For poor retention, the two figures are relatively similar. However, for signs associated with more emotional and behavioral problems, participants were more likely to report these as signs they believed might be associated with poor WM than to report them as signs they had actually observed in children with poor WM. This may reflect some assumptions about children with poor working memory that are not necessarily borne out by direct observations in the classroom.

There were also large individual differences in the number of strategies reported (Range $=0-9$ ), with some answers exhibiting clear evidence of creative practice. For example, "Using an iPad to record a sentence which the child can listen to as many times as needed while writing", "Basket of resources-pen, pencil, glasses, ruler, etc helped the child to just concentrate on the task rather than all the other things", "Using concrete materials in maths, e.g., blocks, ten frames". The strategies that were reported most frequently, such as physical/visual aids, strategy use, and simplification of material have previously been recommended in the working memory literature (Elliott et al., 2010; Gathercole \& 
Alloway, 2007, 2008). However, in some cases, the level of detail included in responses actually exceeded that provided in the literature. For instance, Gathercole and Alloway's (2008) working memory guide for teachers suggests that educators should increase the familiarity of material that is to be taught. A small number of respondents gave examples of how this might be achieved, such as "pre-teaching", whereby individuals are taught content or skills prior to the lesson, such as important and/or novel vocabulary. This approach has been highlighted as a useful strategy for some other groups, such as children with certain developmental disorders and individuals learning a second language (Chang, 2016; Queensland Government Autism Hub and Reading Centre, 2017). It is easy to see how such an approach may be beneficial for children with poor working memory, as teaching key concepts before the lesson may reduce the processing demands of classroom activities.

A small number of respondents listed strategies for which there is currently little or inconsistent evidence for their efficacy, such as working memory training. Recent meta-analyses of working memory training studies show that whilst children do improve on the working memory tasks they have been trained on, there is no compelling, consistent evidence that this then transfers to improved academic outcomes (Melby-Lervåg \& Hulme, 2013; Shipstead et al., 2012). However, only about 5\% of respondents mentioned working memory training, and even fewer participants reported they had applied the strategy (3.6\%). Perhaps of more note is that over $20 \%$ of respondents did not report any strategies, with a further $12 \%$ of respondents only reported one. These numbers were even larger when considering the strategies that individuals reported applying, with over $40 \%$ listing zero strategies, and a further $21 \%$ listing one. This shows the need to continue to improve the dissemination of evidence-informed guidance to those working in education, to enable them to support children with poor working memory.

\subsection{Recommendations for practice}

The outcomes of this study have important implications for teacher-training programs and schools. From the current study, it is clear that at least in the UK, teacher-training courses do not typically include content about working memory. This is likely to result in educational professionals learning about working memory through experience in the classroom, which may result in an incomplete understanding of key aspects of working memory (as demonstrated within the current study in relation to duration limits). Given that working memory impairments are relatively prevalent (affecting 10-15\% of school-aged children; Gathercole \& Alloway, 2008; Holmes et al., 2010), and affect both classroom engagement and academic achievement (Alloway \& Alloway, 2010; Gathercole, Pickering, Knight, \& Stegmann, 2004b; Holmes \& Adams, 2006), we suggest that working memory should be a fundamental concept taught during teacher-training courses. This should include basic information about working memory (e.g. the definition, capacity, and duration), its importance for learning, signs of impairment, and strategies to help children with poor working memory. It would also be useful to inform teachers that children with a range of developmental disorders, such as Autism Spectrum Disorder, ADHD, dyslexia and DCD are particularly at risk of poor working memory (Alloway \& Archibald, 2008; Beneventi et al., 2010; Martinussen et al., 2005; Smith-Spark \& Fisk, 2007). Providing training within teacher training programs would ensure that educators who arguably have the most important role in children's learning are aware of working memory and can support children with impairments to reach their potential.

Finally, when seeking to improve understanding of working memory in schools, a collaborative approach between researchers and educators should be used. Many of the teachers and educational professionals responding to this survey listed creative and useful strategies for supporting children with poor working memory. Identifying methods of best practice within schools, and linking these to the recommendations from research, will provide a richer evidence-base which can then be used to better support children in the classroom.

\subsection{Strengths, limitations and suggestions for further research}

A strength of this study is that the sample was large and diverse in nature ( $N=1425$ vs 14 used in previous research; Alloway et al., 2012), covering a variety of different roles within schools, such as classroom teachers, teaching assistants, SENCOs, and members of senior leadership teams. This is a novel aspect, with research to date only assessing awareness in classroom teachers (Alloway et al., 2012). Furthermore, the study involved a large number of respondents from both primary and secondary schools, ${ }^{3}$ with previous work investigating understanding in primary school teachers only (Alloway et al., 2012).

The study did, however, have some limitations. First, categorizing free-text responses always presents challenges, and inevitably involves an element of subjectivity. This was particularly the case with the definition question, and therefore caution must be taken when considering the categories created. However, much of this difficulty stems from the fact that respondents often gave answers that were vague or ambiguous, which itself suggests that many respondents had an incomplete understanding of working memory. Second, the number of correct responses to multiple choice questions is partly dependent on the options presented. For example, with the definition multiple-choice question, we could have written five statements that closely resembled working memory, but where four of them (the lures) contained one item of incorrect information. In that scenario, it is likely that fewer respondents would have selected the correct option. Given the purpose of this questionnaire was to ascertain whether educational professionals understood the key aspects of working memory, rather than an academic test of the complexities of working memory, we chose to write lures that reflected that aim. Third, respondents volunteered to participate after seeing advertisements on social media or from hearing about the study through word of mouth. As such, the respondents may have more experience of children with poor working memory or be more aware of working memory than an average education professional. Indeed, almost all of the respondents reported having experienced a child with poor working memory. However, given that approximately $10-15 \%$ of children have working memory impairments severe enough to affect their educational attainment (Gathercole \& Alloway, 2008; Holmes et al., 2010), it would be predicted that most educational professionals would have encountered a child with poor working memory at some point. Further, even if the self-selection bias meant these respondents were more knowledgeable about working memory than the average person working in education, this shows that training on working memory is even more important. The results from this survey showed that many respondents struggled to provide a clear definition of working memory or held key misconceptions about the duration information can be held. As such, if further data could be collected in a way that overcame selfselection bias, then we would likely see more misunderstanding

\footnotetext{
${ }^{3}$ In the UK, primary school is from 4 to 11 years and secondary school is from 11 to 16 years. Some schools have a sixth form attached, which is from 16 to 18 years. Attendance at primary and secondary school is compulsory, whilst sixth form is not. Primary schools may have a nursery attached.
} 
about aspects of working memory.

\section{Conclusions}

In summary, the current study investigated awareness and understanding of working memory in a large sample of educational professionals. Educators were generally aware that working memory had a limited capacity and were able to identify the correct definition of working memory from a list. However, respondents generally struggled to spontaneously provide a clear definition of working memory and overestimated the duration over which information could be held. The vast majority of respondents could identify at least two signs of working memory impairment, and around two-thirds could list two or more strategies to help children with poor working memory. There were, however, large individual differences, with some respondents listing eight or nine strategies, whilst others did not list any. Taken together, this demonstrates that educational professionals generally have a basic, but incomplete understanding about working memory. Given the misconceptions identified, and the large individual differences in understanding observed, educational professionals should be given further training about this core component of cognition and how it relates to academic progress and pedagogic practice.

\section{Author information}

The authors would like to thank Roisin Flynn and Anisha De Silva for help with data processing. The project was started during ALA's PhD, which was funded by an Economic and Social Research Council PhD Studentship. ALA then continued working on the project at the Centre for Applied Education Research (CAER). One of the authors of this paper (AHW) was supported by the National Institute for Health Research Yorkshire and Humber ARC (reference: NIHR20016). The data are freely available at: https://osf.io/ $638 \mathrm{dw} /$.

\section{Appendix A. Supplementary data}

Supplementary data to this article can be found online at https://doi.org/10.1016/j.tate.2021.103343.

\section{References}

Alloway, T. P. (2006). How does working memory work in the classroom? Educational Research and Reviews, 1(4), 134-139.

Alloway, T. P. (2007). Working memory, reading, and mathematical skills in children with developmental coordination disorder. Journal of Experimental Child Psychology, 96(1), 20-36. https://doi.org/10.1016/j.jecp.2006.07.002

Alloway, T. P., \& Alloway, R. G. (2010). Investigating the predictive roles of working memory and IQ in academic attainment. Journal of Experimental Child Psychology, 106(1), 20-29. https://doi.org/10.1016/j.jecp.2009.11.003

Alloway, T. P., Alloway, R. G., \& Wootan, S. (2014). Home sweet home: Does where you live matter to working memory and other cognitive skills? Journal of Experimental Child Psychology, 124, 124-131. https://doi.org/10.1016/ j.jecp.2013.11.012

Alloway, T. P., \& Archibald, L. (2008). Working memory and learning in children with developmental coordination disorder and specific language impairment. Journal of Learning Disabilities, 41(3), 251-262. https://doi.org/10.1177/ 0022219408315815

Alloway, T. P., Doherty-Sneddon, G., \& Forbes, L. (2012). Teachers perceptions of classroom behaviour and working memory. Educational Research and Reviews, 7(6), 138-142.

Alloway, T. P., Gathercole, S. E., Kirkwood, H., \& Elliott, J. (2008). Evaluating the validity of the automated working memory assessment. Educational Psychology, 28(7), 725-734. https://doi.org/10.1080/01443410802243828

Alloway, T. P., Gathercole, S. E., Kirkwood, H., \& Elliott, J. (2009). The cognitive and behavioral characteristics of children with low working memory. Child Development, 80(2), 606-621. https://doi.org/10.1111/j.1467-8624.2009.01282.x

Archibald, L. M., \& Gathercole, S. E. (2006). Short-term and working memory in specific language impairment. International Journal of Language \& Communication Disorders, 41(6), 675-693. https://doi.org/10.1080/13682820500442602
Baddeley, A. (2012). Working memory: Theories, models, and controversies. Annual Review of Psychology, 63, 1-29.

Baddeley, A., Hitch, G., \& Allen, R. (2021). A multicomponent model of working memory. In R. Logie, V. Camos, \& N Cowan (Eds.), Working memory: The state of the science. Oxford University Press.

Barrouillet, P., \& Camos, V. (2015). Essays in cognitive psychology. Working memory: Loss and reconstruction. Psychology Press.

Barrouillet, P., \& Camos, V. (2021). The time-based resource-sharing model of working memory. In R. Logie, V. Camos, \& N.( Cowan (Eds.), Working memory: The state of the science. Oxford University Press.

Beneventi, H., Tønnessen, F. E., Ersland, L., \& Hugdahl, K. (2010). Working memory deficit in dyslexia: Behavioral and FMRI evidence. International Journal of Neuroscience, 120(1), 51-59. https://doi.org/10.3109/00207450903275129

Berry, E. D., Allen, R. J., Mon-Williams, M., \& Waterman, A. H. (2019). Cognitive offloading: Structuring the environment to improve children's working memory task performance. Cognitive Science, 43(8), Article e12770. https://doi.org/ $10.1111 /$ cogs. 12770

Cain, K., Oakhill, J., \& Bryant, P. (2004). Children's reading comprehension ability: Concurrent prediction by working memory, verbal ability, and component skills. Journal of Educational Psychology, 96(1), 31-42. https://doi.org/10.1037/ 0022-0663.96.1.31

Chang, A. C. S. (2016). Teaching L2 listening: In and outside the classroom. In W. Renandya, \& H. Widodo (Eds.), English language teaching today. English language education (pp. 111-125). Springer. https://doi.org/10.1007/978-3-31938834-2_9.

Cowan, N. (1999). An embedded process model of working memory. In A. Miyake (Ed.).

Cowan, N. (2014). Working memory underpins cognitive development, learning and education. Educational Psychology Review, 26(2), 197-223. https://doi.org/ 10.1007/s10648-013-9246-y

Cowan, N. (2017). The many faces of working memory and short-term storage. Psychonomic Bulletin \& Review, 24(4), 1158-1170. https://doi.org/10.3758/ s13423-016-1191-6

Cowan, N., Morey, C. C., \& Naveh-Benjamin, M. (2021). An Embedded-Processes Approach to Working Memory: How is it distinct from other approaches, and to what ends? In R. Logie, V. Camos, \& N.( Cowan (Eds.), Working memory: The state of the science. Oxford University Press.

Dunning, D. L., \& Holmes, J. (2014). Does working memory training promote the use of strategies on untrained working memory tasks? Memory \& Cognition, 42(6), 854-862. https://doi.org/10.3758/s13421-014-0410-5

Elliott, J. G., Gathercole, S. E., Alloway, T. P., Holmes, J., \& Kirkwood, H. (2010). An evaluation of a classroom-based intervention to help overcome working memory difficulties and improve long-term academic achievement. Journal of Cognitive Education and Psychology, 9(3), 227-250. https://doi.org/10.1891/ 1945-8959.9.3.227

Fürst, A. J., \& Hitch, G. J. (2000). Separate roles for executive and phonological components of working memory in mental arithmetic. Memory \& Cognition, 28(5), 774-782. https://doi.org/10.3758/BF03198412

Gathercole, S. E., \& Alloway, T. P. (2007). Understanding working memory: A classroom guide. Harcourt Assessment.

Gathercole, S., \& Alloway, T. P. (2008). Working memory and learning: A practical guide for teachers. Sage.

Gathercole, S. E., Durling, M., Evans, S., Jeffcock, E., \& Stone, S. (2008). Working memory abilities and children's performance in laboratory analogues of classroom activities. Applied Cognitive Psychology, 22, 1019-1037. https://doi.org/ 10.1002/acp.1407

Gathercole, S. E., Lamont, E., \& Alloway, T. P. (2006). Working memory in the classroom. In S. Pickering (Ed.), Working memory and education (pp. 219-240). Elsevier Press.

Gathercole, S. E., Pickering, S. J., Ambridge, B., \& Wearing, H. (2004a). The structure of working memory from 4 to 15 years of age. Developmental Psychology, 40(2), 177-190. https://doi.org/10.1037/0012-1649.40.2.177

Gathercole, S. E., Pickering, S. J., Knight, C., \& Stegmann, Z. (2004b). Working memory skills and educational attainment: Evidence from national curriculum assessments at 7 and 14 years of age. Applied Cognitive Psychology: The Official Journal of the Society for Applied Research in Memory and Cognition, 18(1), 1-16. https://doi.org/10.1002/acp.934

Holmes, J., \& Adams, J. W. (2006). Working memory and children's mathematical skills: Implications for mathematical development and mathematics curricula. Educational Psychology, 26(3), 339-366. https://doi.org/10.1080/ 01443410500341056

Holmes, J., Gathercole, S. E., \& Dunning, D. L. (2010). Poor working memory: Impact and interventions. In Advances in child development and behavior (Vol. 39, pp. $1-43)$.

Jaroslawska, A. J., Gathercole, S. E., Logie, M. R., \& Holmes, J. (2016). Following instructions in a virtual school: Does working memory play a role? Memory \& Cognition, 44(4), 580-589. https://doi.org/10.3758/s13421-015-0579-2

Kirschner, P. A. (2017). Stop propagating the learning styles myth. Computers \& Education, 106, 166-171. https://doi.org/10.1016/j.compedu.2016.12.006

Klingberg, T., Fernell, E., Olesen, P. J., Johnson, M., Gustafsson, P., Dahlström, K., et al. (2005). Computerized training of working memory in children with ADHD-a randomized, controlled trial. Journal of the American Academy of Child \& Adolescent Psychiatry, 44(2), 177-186. https://doi.org/10.1097/00004583200502000-00010

Kyttälä, M., Kanerva, K., Munter, I., \& Björn, P. M. (2019). Working memory resources in children: Stability and relation to subsequent academic skills. Educational 
Psychology, 39(6), 709-728. https://doi.org/10.1080/01443410.2018.1562046

Martinussen, R., Hayden, J., Hogg-Johnson, S., \& Tannock, R. (2005). A meta-analysis of working memory impairments in children with attention-deficit/ hyperactivity disorder. Journal of the American Academy of Child \& Adolescent Psychiatry, 44(4), 377-384. https://doi.org/10.1097/01.chi.0000153228.72591.73

Melby-Lervåg, M., \& Hulme, C. (2013). Is working memory training effective? A meta-analytic review. Developmental Psychology, 49(2), 270-291. https:// doi.org/10.1177/1745691616635612

Miller, G. A. (1956). The magical number seven plus or minus two: Some limits on our capacity for processing information. Psychological Review, 63(2), 81-97.

Morrison, A. B., \& Chein, J. M. (2011). Does working memory training work? The promise and challenges of enhancing cognition by training working memory. Psychonomic Bulletin \& Review, 18(1), 46-60. https://doi.org/10.3758/s13423010-0034-0

Pashler, H., McDaniel, M., Rohrer, D., \& Bjork, R. (2008). Learning styles: Concepts and evidence. Psychological Science in the Public Interest, 9(3), 105-119. https:// doi.org/10.1111/j.1539-6053.2009.01038.x

Preßler, A.-L., Könen, T., Hasselhorn, M., \& Krajewski, K. (2014). Cognitive preconditions of early reading and spelling: A latent-variable approach with longitudinal data. Reading and Writing, 27(2), 383-406. https://doi.org/10.1007/ s11145-013-9449-0

Queensland Government Autism Hub and Reading Centre. (2017). Pre-teaching. https://ahrc.eq.edu.au/services/fba-tool/help/pre-teaching.

Rowe, A., Titterington, J., Holmes, J., Henry, L., \& Taggart, L. (2019). Interventions targeting working memory in 4-11 year olds within their everyday contexts: A systematic review. Developmental Review, 52, 1-23. https://doi.org/10.1016/ j.dr.2019.02.001

Sala, G., \& Gobet, F. (2017). Working memory training in typically developing children: A meta-analysis of the available evidence. Developmental Psychology, 53(4), 671-685. https://doi.org/10.1037/dev0000265

Shipstead, Z., Redick, T. S., \& Engle, R. W. (2012). Is working memory training effective? Psychological Bulletin, 138(4), 628-654. https://doi.org/10.1037/ a0027473

Smith-Spark, J. H., \& Fisk, J. E. (2007). Working memory functioning in developmental dyslexia. Memory, 15(1), 34-56. https://doi.org/10.1080/ 09658210601043384

Waterman, A. H., Atkinson, A. L., Aslam, S. S., Holmes, J., Jaroslawska, A., \& Allen, R. J. (2017). Do actions speak louder than words? Examining children's ability to follow instructions. Memory \& Cognition, 45(6), 877-890. https://doi.org/ 10.3758/s13421-017-0702-7

Yang, T. X., Allen, R. J., Holmes, J., \& Chan, R. C. (2017). Impaired memory for instructions in children with attention-deficit hyperactivity disorder is improved by action at presentation and recall. Frontiers in Psychology, 8, 39. https:/ doi.org/10.3389/fpsyg.2017.00039

Yang, T. X., Allen, R. J., Waterman, A. H., Zhang, S. Y., Su, X. M., \& Chan, R. C. (2021). Comparing motor imagery and verbal rehearsal strategies in children's ability to follow spoken instructions. Journal of Experimental Child Psychology, 203. https://doi.org/10.1016/j.jecp.2020.105033 